Harrington, M. G. (1958). J. gen. Microbiol. 18, 767-773

\title{
The Action of Ghloramphenicol on Protein and Nucleic Acid Synthesis by Escherichia coli Strain B
}

\author{
BY M. G. HARRINGTON* \\ Department of Biochemistry, University of Cambridge
}

SUMMARY: Growth-inhibitory concentrations of chloramphenicol caused a prompt inhibition of protein synthesis in Escherichia coli strain B. This inhibition was accompanied by alteration in nucleic acid synthesis from a logarithmic to a linear rate, and by the excretion into the medium of free purine and pyrimidine bases, three of which were identified as guanine, hypoxanthine and uracil. At slightly lower concentrations the antibiotic caused a slight stimulation of nucleic acid synthesis.

Gale \& Folkes $(1953 b)$ showed that chloramphenicol at bactericidal concentrations exerted a specific inhibition of protein synthesis by washed suspensions of Staphylococcus aureus. Such concentrations stimulated nucleic acid synthesis and were without effect on glucose fermentation. Wisseman, Smadel, Hahn \& Hopps (1954) with Escherichia coli showed that the antibiotic promptly inhibited protein synthesis while allowing nucleic acid synthesis to continue 'temporarily unabated'. Ammonia assimilation was also largely suppressed, but continued at a rate compatible with nucleic acid formation. The present paper describes the results of related studies carried out with $E$. coli strain B.

\section{METHODS}

Organism and growth conditions. The organism used throughout this work was Escherichia coli strain B. It was maintained by daily subculture in a glucose + inorganic salts medium (Abelson, Bolton \& Aldous, 1952), modified by increasing the content of $\mathrm{Na}_{2} \mathrm{HPO}_{4}$ to $9.0 \mathrm{~g} . / \mathrm{l}$., and of $\mathrm{KH}_{2} \mathrm{PO}_{4}$ to $4.5 \mathrm{~g}$./1.; glucose was present at a concentration of $0.5 \%(w / v)$. Organisms grown in the above medium for $15 \mathrm{hr}$. at $37^{\circ}$ in Roux bottles were harvested on the centrifuge, washed twice in $0.85 \%(\mathrm{w} / \mathrm{v}) \mathrm{NaCl}$ solution and suspended in saline to a concentration equivalent to $45 \mathrm{mg}$. dry wt. organism $/ \mathrm{ml}$. Dry weights of suspensions of organisms were estimated turbidimetrically by using an Hilger adsorptiometer and a previously prepared calibration curve of optical density against equivalent dry weight of suspensions of the organism.

Growth-inhibition coefficients. The minimum growth inhibitory concentration of chloramphenicol was determined by inoculating with $c .10^{6}$ organisms/ $5.0 \mathrm{ml}$., tubes containing serial dilutions of chloramphenicol in growth medium. These tubes were incubated at $37^{\circ}$ for $48 \mathrm{hr}$. Using turbidity to the naked eye as the criterion of growth, it was found that growth of the organism was inhibited by $3.0 \mu \mathrm{g}$. chloramphenicol $/ \mathrm{ml}$.

* Present address : Department of Biochemistry and Pharmacology, University College, Dublin. 
Synthesis of protein and nucleic acid. Optimum synthesis of protein and nucleic acid occurred when organisms prepared as above were incubated at a concentration equivalent to $1.5 \mathrm{mg}$. dry weight organism $/ \mathrm{ml}$. in growth medium at $37^{\circ}$ with vigorous aeration. The synthesis of these components which occurred in the presence of different concentrations of chloramphenicol was compared with that observed in a control without chloramphenicol.

Estimation of protein. Organisms were centrifuged from $5.0 \mathrm{ml}$. portions of the incubation mixtures, washed twice in saline and resuspended in water. The protein was precipitated by the addition of an equal volume of cold $10 \%(\mathrm{w} / \mathrm{v})$ trichloroacetic acid (TCA). The mixture was stored at $0^{\circ}$ for $1 \mathrm{hr}$, the precipitate separated and washed with cold $5 \%(\mathrm{w} / \mathrm{v})$ trichloroacetic acid. The protein was hydrolysed with $6 \mathrm{~N}-\mathrm{HCl}$ for $15 \mathrm{hr}$. at $105^{\circ}$ in sealed tubes. Excess hydrochloric acid was removed in vacuo and the residue suspended in $0.2 \mathrm{M}$-sodium acetate buffer ( $\mathrm{pH} \mathrm{4.5)}$. The glutamic acid of the hydrolysate was determined by using the specific decarboxylase method of Gale (1945). This value for 'combined glutamate' was taken as a measure of the protein content of the organisms (Gale \& Folkes, 1953a).

Estimation of nucleic acid. The nucleic acid content of the organisms was determined by using the trichloroacetic acid-precipitable fraction of whole organisms prepared as above. After washing with cold $5 \%(w / v)$ trichloroacetic acid, the residue was extracted with three successive $2.0 \mathrm{ml}$. portions of $5.0(\mathrm{w} / \mathrm{v})$ trichloroacetic acid at $90^{\circ}$ for $10 \mathrm{~min}$. The optical density at $260 \mathrm{~m} \mu$. of suitable dilutions of the combined extracts was determined against a trichloroacetic acid blank similarly treated. The nucleic acid content of the organisms was calculated by assuming an extinction coefficient of 24 for a $0.1 \%$ solution of nucleic acid (Gale \& Folkes, 1954). All ultraviolet absorption determinations were carried out with a Beckman spectrophotometer model DU.

Analysis of the medium. The incubation medium, after removal of the organ $\approx$ isms fluoresced under u.v. light and absorbed strongly in the region 240$260 \mathrm{~m} \mu$. On repeated freeze-drying, after addition of excess $\mathrm{NaOH}$ to remove ammonia, the residue gave a positive ninhydrin reaction. The fluorescent and u.v.-absorbing constituents of the medium were removed from solution by adsorption on to activated charcoal (pre-treated as described by Partridge \& Brimley, 1952). The adsorbed components were eluted with $5 \%(\mathrm{w} / \mathrm{v})$ phenol in $20 \%(v / v)$ acetic acid. The phenol was extracted with ether and the acetic acid removed by evaporation to dryness in vacuo. The residue was dissolved in the minimum amount of distilled water. Single dimensional chromatograms were prepared and developed with the following solvents: $n$-butanol + formic acid + water (77:10:13), n-propanol +0.02 M-potassium acetate (pH 6.0) $(70: 30)$, isopropanol + water $(65: 35)$ containing $2 \mathrm{~N}-\mathrm{HCl}$. The dried papers were examined under u.v. radiation and the areas of fluorescence outlined. The positions of the u.v.-absorbing components were determined by preparing direct contact prints on Ilford Document Paper, using a mercury discharge lamp (Thermal Syndicate Ltd., T/M5/369) as u.v. source. The corresponding areas on the chromatograms were cut out and eluted with $0 \cdot 1 \mathrm{~N}-\mathrm{HCl}$ and the 
adsorption spectra of the compounds determined against similar eluates of equivalent blank strips of paper cut from the chromatograms. Duplicate papers run in the same solvents were dryed and sprayed with $0 \cdot 1 \%(\mathrm{w} / \mathrm{v})$ ninhydrin in chloroform and heated at $100^{\circ}$ for $5 \mathrm{~min}$.

\section{RESULTS}

When suspensions of Escherichia coli strain B were incubated as described above growth and the synthesis of protein and nucleic acid proceeded at a logarithmic rate with a mean generation time of 70-90 min. Progress curves for the inhibition of protein and nucleic acid synthesis by different concentrations of chloroamphenicol were determined. The synthesis of protein is very sensitive to chloramphenicol, being completely inhibited by $3 \cdot 0 \mu \mathrm{g}$. chloramphenicol $/ \mathrm{ml}$. (Fig. 1). The corresponding results for the inhibition of nucleic acid synthesis (Fig. 2) indicated that low concentrations of chloramphenicol altered the rate of synthesis from a logarithmic to a linear rate, and that increasing the concentration of chloramphenicol merely decreased the time before the onset of this alteration.

Wisseman et al. (1954) reported that chloramphenicol promptly inhibited protein synthesis in Escherichia coli, whereas the synthesis of nucleic acid was unaffected even at concentrations much greater than that which inhibited

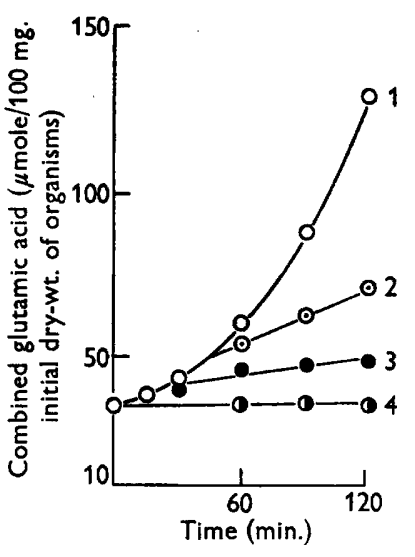

Fig. 1

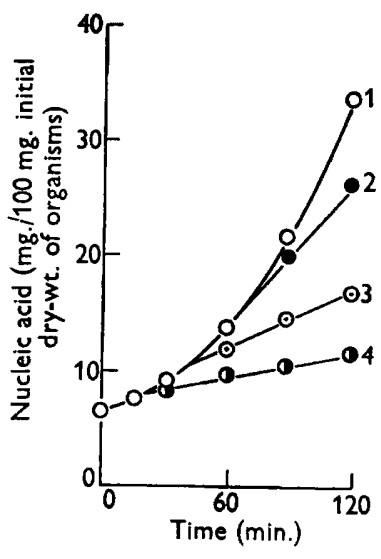

Fig. 2

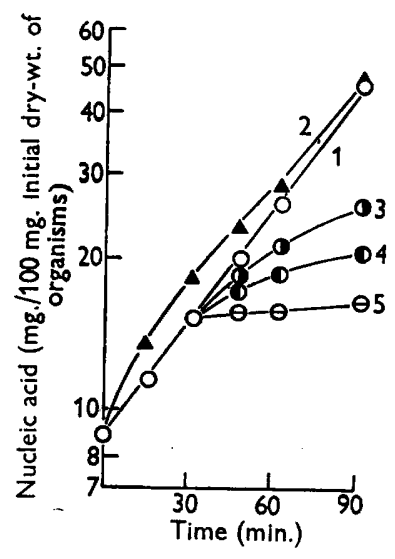

Fig. 3

Fig. 1. Progress curves for the response of protein synthesis in Escherichia coli strain $B$ to different concentrations of chloramphenicol: curve $1,0-0,0$ to $0.1 \mu \mathrm{g} . / \mathrm{ml}$; curve 2 ,

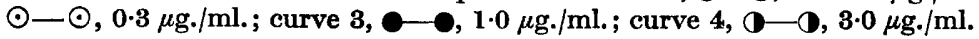

Fig. 2. Progress curves for the response of nucleic acid synthesis in Escherichia coli strain B to different concentrations of chloramphenicol : curve $1,0-0,0$ to $0.3 \mu \mathrm{g}$. $/ \mathrm{ml}$.; curve 2 , $-1.0 \mu \mathrm{g} . / \mathrm{ml}$; ; curve $3, \odot-\odot, 3.0 \mu \mathrm{g} . / \mathrm{ml}$. ; curve $4, \odot-1,10.0 \mu \mathrm{g} . / \mathrm{ml}$.

Fig. 3. Progress curves for the response to different concentrations of chloramphenicol, of nucleic acid synthesis in Escherichia coli strain $B$ which had been preincubated in growth medium until logarithmic growth was established. Curve 1, $\mathrm{O}_{-} \mathrm{O}$, shows the rate of synthesis in control without chloramphenicol; for the other curves the incubation mixtures contained chloramphenicol: curve $2, \Delta-\Delta, 1.0 \mu \mathrm{g} . / \mathrm{ml}$; curve 3 , $\bigcirc-0,3.0 \mu \mathrm{g} . / \mathrm{ml}$; ; curve 4, $\bigcirc-1,10 \cdot 0 \mu \mathrm{g} . / \mathrm{ml}$. ; curve $5, \ominus-\Theta, 30.0 \mu \mathrm{g} . / \mathrm{ml}$. 
growth. In view of the apparent discrepancy between the results of these workers and those reported here, an experiment was carried out under conditions similar to those described by Wisseman et al. (1954). This involved the incubation of the organisms, after harvesting, in medium without chloramphenicol 'until the logarithmic rate of growth was well established' (90 min.). Chloramphenicol was then added and the effects studied over a period of $90 \mathrm{~min}$. As before, it was found that protein synthesis was completely inhibited by concentrations of chloramphenicol greater than $3.0 \mu \mathrm{g} . / \mathrm{ml}$. The observed effects on the synthesis of nucleic acid (Fig. 3) show that, as reported by Wisseman et al. (1954), growth inhibitory and higher concentrations of chloramphenicol exerted little action on the process during the first $30 \mathrm{~min}$. Thereafter, however, the response was governed by the concentration of the drug, and this effect may have represented a direct inhibition of the process which was exhibited only after an initial lag of $\mathbf{3 0} \mathrm{min}$.

Gale \& Folkes $(\mathbf{1 9 5 3} b)$ showed that in suspensions of Staphylococcus aureus concentrations of chloramphenicol which completely inhibited protein synthesis caused a marked stimulation of nucleic acid synthesis. Wisseman et al. (1954) did not observe a similar effect with Escherichia coli. In the present work a slight but reproducible increase in nucleic acid production occurred with $1.0 \mu \mathrm{g}$. chloramphenicol $/ \mathrm{ml}$. (Fig. 3, curve 3). Under these conditions protein synthesis was considerably decreased (Fig. 1, curve 2). This concentration of chloramphenicol also caused a considerable increase in the u.v. absorption of the medium as compared with that in the control suspension. In both cases this increased absorption continued for at least $120 \mathrm{~min}$., and samples of the media were therefore taken for analysis after this interval. The absorption spectra of $1 / 2$ aqueous dilutions of the samples, as well as those of undiluted samples after treatment with activated charcoal, are shown in Fig. 4. Eluates of the charcoal were prepared and diluted so that comparable spectra were obtained (Fig. 5). Both sets of results indicated the presence of ' $260 \mathrm{~m} \mu$.absorbing material', possibly free or combined purine or pyrimidine derivatives in the medium from the chloramphenicol-treated suspension.

Two dimensional chromatograms of the concentrated eluates revealed several ninhydrin-reacting substances, three of which were identified on the basis of their $R_{F}$ values as valine, leucine and methionine. As there was no apparent difference between the samples with and without chloramphenicol, further analysis was not undertaken. Ultraviolet photographs of singledimensional chromatograms showed at least four substances which absorbed radiation in the region of $260 \mathrm{~m} \mu$. in the chloramphenicol-treated suspension. On the basis of $\boldsymbol{R}_{F}$ values (Table 1), and by applying the principle that the logarithmic plot of the extinction of a compound at concentrations which obey De Beer's Law is independent of concentration, the presence of three bases guanine, hypoxanthine and uracil was shown (Harrington, 1954). The quantitative aspect of the appearance of these free bases in the supernatant medium has not been examined. 


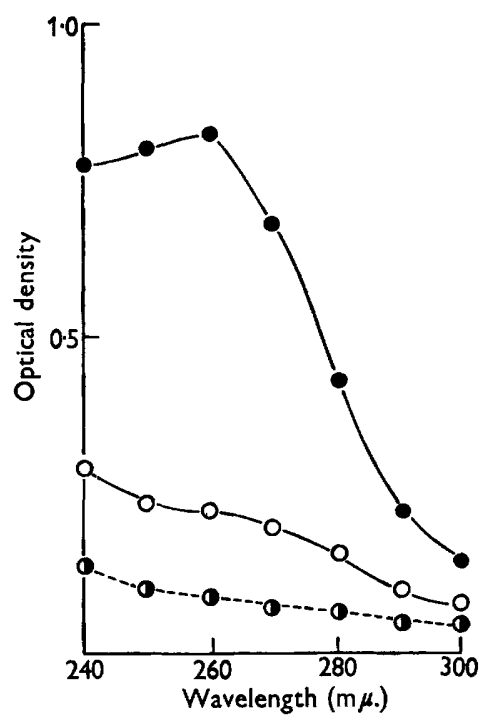

Fig. 4

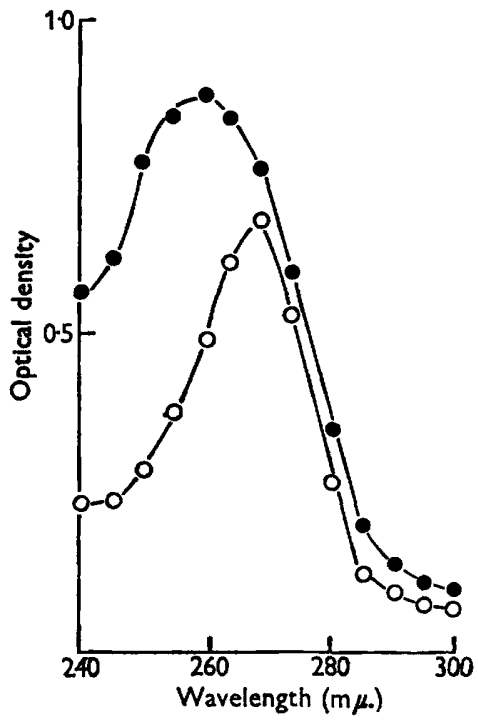

Fig. 5

Fig. 4. Absorption spectra of $1 / 2$ aqueous dilutions of the supernatant fluid from incubations of Escherichia coli strain B in the absence $\left(\mathrm{O}_{-} \mathrm{O}\right)$ and in the presence $\left(\mathrm{O}_{-}\right)$of $1.0 \mu \mathrm{g}$. chloramphenicol $/ \mathrm{ml}$. The broken line (1...-() shows spectrum of undiluted samples after treatment with charcoal.

Fig. 5. Absorption spectra of 'corresponding dilutions' of the charcoal eluates prepared from the supernatant fluids from control $(\mathrm{O}-\mathrm{O})$ and chloramphenicol-containing incubations of Escherichia coli strain B (-) . Dilutions were made to give spectra with closely similar extinctions.

\section{Table 1. Identification of u.v.-absorbing compounds}

$\boldsymbol{R}_{\boldsymbol{F}}$ values of the 'unknown' bases excreted into the medium by chloramphenicol-treated Escherichia coli strain B (column A); values for the pure bases reported by Markham \& Smith (1949; column B); solvent N-butanol + formic acid + water.

A

Guanine
Hypoxanthine
Uracil

Guanine
Hypoxanthine Uracil

\section{A}

$0 \cdot 12-0 \cdot 15$

$0 \cdot 30-0 \cdot 35$

$0 \cdot 40-0 \cdot 42$
B

$\mathbf{0 \cdot 1 3}$

$0 \cdot 30$

$\mathbf{0 . 3 9}$

\section{DISCUSSION}

Gale \& Folkes $(1953 b)$ showed that in Staphylococcus aureus chloramphenicol exerted a specific inhibition of protein synthesis. The results presented here (Figs. 1, 2) indicate that in Escherichia coli strain B there is a close parallelism between the sensitivities of protein and nucleic acid synthesis. While this difference in the behaviour of the two organisms may represent a fundamental distinction between the Gram-positive and Gram-negative species, it seems more likely that it arose from the differences in the experimental conditions. The studies on Staphylococcus aureus were carried out under conditions which allowed the analysis of the two relevant synthetic reactions uncomplicated by other processes of growth. In the present system both reactions were 
occurring as part of normal growth, and consequently may have been interdependent. This latter interpretation is clearly supported by the progress curves for the synthesis of nucleic acid. The continued formation of nucleic acid at a logarithmic rate may require the simultaneous continued production of the necessary enzymes, which ${ }_{i}$ presumably are protein in nature. Thus any specific inhibition of protein synthesis, in the absence of an effect on the activity of existing enzyme protein, might be expected to produce a result similar to that reported in Fig. 2. That this effect was not observed by Wisseman et al. (1954) under very similar conditions may have arisen from variations in the initial nucleic acid content, or in the ratio of protein to nucleic acid content of the organisms.

Britten (1954) showed that during rapid growth Escherichia coli strain B excreted into the medium a complex mixture of metabolic products, including amino acids, but in which carbon dioxide and acetate predominated. Dunlop (1949) reported that under certain conditions some amino acids, notably valine, leucine and methionine, might occur in detectable amounts; similar findings have been reported here. Certain concentrations of chloramphenicol caused the appearance in the medium of free purine and pyrimidine bases. Since under these conditions nucleic acid was being synthesized it seemed unlikely that these bases arose from a depolymerization of cell nucleic acid. In fact with slightly lower concentrations of chloramphenicol a stimulation of nucleic acid production was observed. It is possible that for Escherichia coli strain B the combined effects of chloramphenicol on nucleic acid synthesis and on the excretion of free bases may be the manifestation of an effect corresponding to the stimulation of nucleic acid synthesis in Staphylococcus aureus reported by Gale \& Folkes (1953b). It seems more likely, however, that the observed effects are the results of a series of reactions consequent on the inhibition of protein synthesis by chloramphenicol. Thus, should nucleic acid polymerization require the presence of a protein template (Haurowitz, 1950) the cessation of protein synthesis might lead to saturation of the existing template. The continued production of the purine and pyrimidine bases, a process insensitive to the drug, would then be followed by the excretion of excess bases into the medium.

I wish to express my sincere thanks to Dr E. F. Gale, F.R.S., for his interest and advice throughout this work and to Dr K. McQuillen and Dr R. Davies for many helpful discussions. The work was carried out during the tenure of the Travelling Studentship in Biochemistry (1952) from the National University of Ireland.

\section{REFERENCES}

Abelson, P. H., Bolton, E. T. \& Aldous, E. (1952). The utilization of carbon dioxide in the synthesis of protein by Escherichia coli. J. biol. Chem. 198, 165.

Britten, R. (1954). Extracellular metabolic products of Escherichia coli during rapid growth. Science, 119, 578.

Dunlop, S. G. (1949). The synthesis of amino acids by Escherichia coli in pure cultures. J. Bact. 58, 457 .

Gale, E. F. (1945). Studies on bacterial amino acid decarboxylases. Biochem. $J$. $39,45$. 
Gale, E. F. \& Folkes, J. P. (1953a). The assimilation of amino acids by bacteria. 14. Nucleic acid and protein synthesis in Staphylococcus aureus. Biochem. J. $53,483$.

Gale, E. F. \& Folkes, J. P. (1953b). The assimilation of amino acids by bacteria. 15. Actions of antibiotics on nucleic acid and protein synthesis in Staphylococcus aureus. Biochem. J. 53, 493.

GaLe, E. F. \& Folkes, J. P. (1954). Effects of nucleic acids on protein synthesis and amino acid incorporation in disrupted staphylococcal cells. Nature, Lond. 173, 1223.

Harrington, M. G. (1954). Ph.D. Thesis; National University of Ireland.

Haurowrxz, F. (1950). Chemistry and Biology of Proteins, 2nd ed. New York: Academic Press.

Markham, R. \& Smith, J. D. (1949). A technique for the identification and estimation of purine and pyrimidine bases, nucleosides and related substances. Biochem. J. 45, 294.

Partridge, S. M. \& Brimley, R. C. (1952). Displacement chromatography on synthetic ion exchange resins. 8. A systematic method for the separation of amino acids. Biochem. J. 51, 628.

Wisseman, C. L., Smadel, J. E., Hahn, F. E. \& Hopps, H. E. (1954). The mode of action of chloramphenicol. 1. Action of chloramphenicol on the assimilation of ammonia and on the synthesis of protein and nucleic acid in Escherichia coli. J. Bact. 67, 662 . 